\title{
Laparoscopic versus Open Appendectomy for Acute Appendicitis in Obese Patients: A Prospective Randomized Study
}

\author{
Mohamed I Kassem, MD; Maher M Elzeiny, MD.
}

\author{
Department of Surgery, Gastrointestinal Surgery Unit, \\ Faculty of Medicine, Alexandria University.
}

Objective: Currently, laparoscopic appendectomy is widely practiced for the management of acute appendicitis. Our aim was to compare the safety and the advantages of laparoscopic versus open appendectomy in obese patients in a prospective randomized study.

Patients and methods: This prospective study was carried on 80 patients from April 2013 to November 2014. Patients were randomly divided into two groups. The group A: 40 patients were subjected to laparoscopic appendectomy (LA), whereas the group B: 40 patients were subjected to open appendectomy (OA). The demography and the primary outcome measures of the patients such as operative duration, hospital stay, post-operative pain, post-operative complications and patient's satisfaction about cosmesis result were recorded and analyzed.

Result: Eighty obese patients with clinical diagnosis of acute appendicitis were included. Operative time was longer in group A (LA) with mean of (77.20 \pm 23.04$)$ in comparison with group $B(O A)(68.40 \pm 6.67)$. Operative difficulties were encountered in $10 \%$ and $20 \%$ of cases in group $A$ and $B$ respectively. No conversion in LA was performed in any case. Patients in group A started feeding earlier (7.30 \pm 2.45 hours) than group B (18.10 \pm 13.25 hours). Mean comparison of postoperative pain by visual analogue scale on day 1 , was significantly lower in Group A (4.0 \pm 1.89$)$ compared with Group B (6.40 \pm 1.71$)$. Length of hospital stay was shorter in Group A (1.35 \pm 0.58 days) than Group B (2.40 \pm 0.57 days). Chest infection was slightly higher in group $B(10 \%)$ in comparison to group $A(7.5 \%)$. The rate of wound infection was higher in OA 20\% in comparison with LA 5\% (especially in perforated appendicitis cases). Patient's satisfaction in term of cosmesis was highler in group A in comparison to group $B$.

Conclusion: Laparoscopic appendectomy is safe and superior to OA in obese patients with respect to an early discharge, lesser postoperative pain, decreased wound infection, early return to work and a better cosmetic scar. Laparoscopic appendectomy also improves diagnostic ability and excludes other causes of abdominal pain and gives the ability to manage other pathology at the same session.

Key words: Laparoscopy, appendicitis, obesity, laparoscopic appendectomy.

\section{Introduction:}

Appendicitis is the most common surgical abdominal emergency all over the world and the second frequently performed abdominal surgery next to cholecystectomy, most commonly occurring in adolescents and young adults with a peak incidence in the second and third decades of life; however appendicitis may affect all ages. ${ }^{1}$ Also, appendicitis is higher among males (male to female ratio of $1.4: 1){ }^{2}$ The rate of appendectomy for appendicitis has remained constant at 10 per 10,000 patients per year. During their lifetime, 6-7\% of individuals will develop acute appendicitis. ${ }^{3}$

For almost a century, open appendectomy (OA), as described by McBurney, ${ }^{2}$ was the gold standard treatment for appendicitis. In the early 1983s, the first laparoscopic appendectomy (LA) was performed and described by Semm. ${ }^{3}$ Since its introduction, the role of laparoscopy for appendicitis has 
been controversial. Several retrospective and prospective studies have shown advantages for LA when compared with OA, ${ }^{4}$ other studies could not demonstrate superiority of the laparoscopic approach.

With the advent of laparoscopy, Laparoscopic surgical techniques have transformed much of surgery over recent decades, minimal access techniques allow extensive operations to be performed with little trauma. ${ }^{5}$ The well established advantages of the laparoscopic approach have enabled this procedure to gain rapid worldwide acceptance over open procedures. ${ }^{6}$

LA has been an increasingly used surgical procedure for acute appendicitis since its introduction in $1983^{3}$ it provides better diagnostic accuracy, reduced use of analgesics, shorter hospital stay, earlier return to daily activities, and a lower rate of wound infection in comparison to OA.7-12 Some investigations have also revealed that elderly patients, morbidly obese patients, and fertile women can take advantage of LA to treat acute appendicitis. ${ }^{13-15}$ In addition, LA is cosmetically beneficial.

However, there is a debated issue regarding septic postoperative complications (e.g., intraabdominal abscess) following LA, especially in cases with complicated appendicitis. ${ }^{16-18}$ Although some studies have concluded that LA is a safe and effective treatment for complicated acute appendicitis. ${ }^{19-23}$

The aim of this work was to compare laparoscopic and open appendectomy for acute nonperforated and perforated appendicitis in obese patients regarding:

- Operative time.

- Technical difficulties.

- Time to tolerate feeding.

- Post-operative pain.

- Post-operative hospital stay.

- Post-operative complication.

- Patient satisfaction regarding cosmesis.

\section{Patients and methods:}

This prospective study was conducted in the Gastrointestinal Surgery Unit, the Alexandria Main University Hospital, from April 2013 to November 2014. Patients with a clinical diagnosis of acute appendicitis were randomized to either LA or OA to reduce the bias of surgical approach. Eighty obese patients with $\mathrm{BMI}>30$, their age ranged between 18-54 years with features suggestive of acute nonperforated and perforated appendicitis, were included in the study. The patients were followed through their hospital course and subsequently for 2-week and then monthly through the outpatient follow-up visits.

Exclusion criteria:

- Appendicular mass.

- Appendicular abscess.

- Previous lower midline abdominal surgery and unfit for laparoscopy.

A detailed history of the patients was taken, and physical examination, a complete blood analysis, urine examination and ultrasound of the abdomen were routinely performed in all the cases. Computerized tomography (CT) was selectively performed in patients with difficult diagnosis. The risks and benefits of the two procedures were explained to the patients and their informed consent was obtained. All the patients were randomly divided into group $\mathrm{A}$ [LA] and group $\mathrm{B}$ [OA], each 40 patients, and the patients were operated under spinal anaesthesia or general anaesthesia.

LA was performed through a three port technique and carbon dioxide was used to create the pneumoperitoneum. The Open Hasson technique or the Veress needle or Visiports optical trocar were used for creating the pneumoperitoneum, followed by a $10 \mathrm{~mm}$ trocar insertion at the supra-umbilical or umbilical region and the other two $5 \mathrm{~mm}$ ports were placed in Lt iliac fossa and suprapubic region. The dissection and mobilization of the appendix were performed by using unipolar coagulation or harmonic shear Figures $(\mathbf{1}, \mathbf{2})$ or Ligature. The appendix was divided at its base between the two endoloops Figure (3), or 3 extracorporeal knots or 3 clips Figures $(4,5)$. The retrieval of the resected inflamed appendix or the inflamed perforated appendix was performed through the umbilical port Figures $(\mathbf{6 , 7 , 8 )}$. OA was performed through a Grid iron incision 


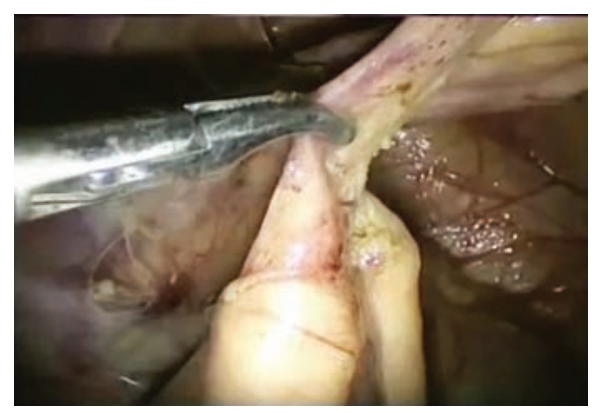

Figure (1): Monopolar diathermy was used to control and dissection the mesoappendix.

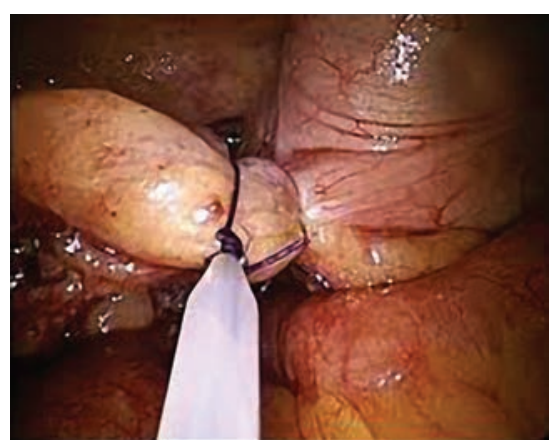

Figure (3): The base of the appendix was ligated using endoloop.

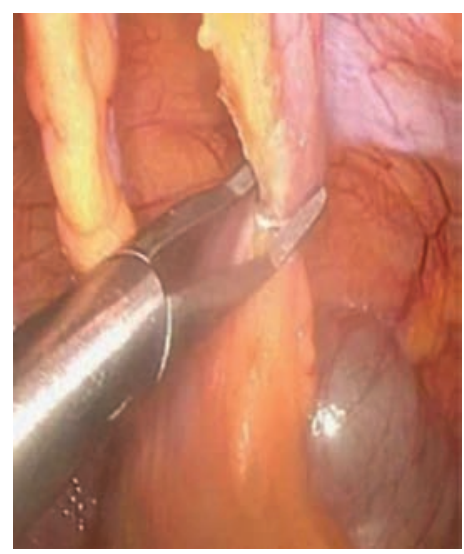

Figure (5): Show applying of clip over appendicular base.

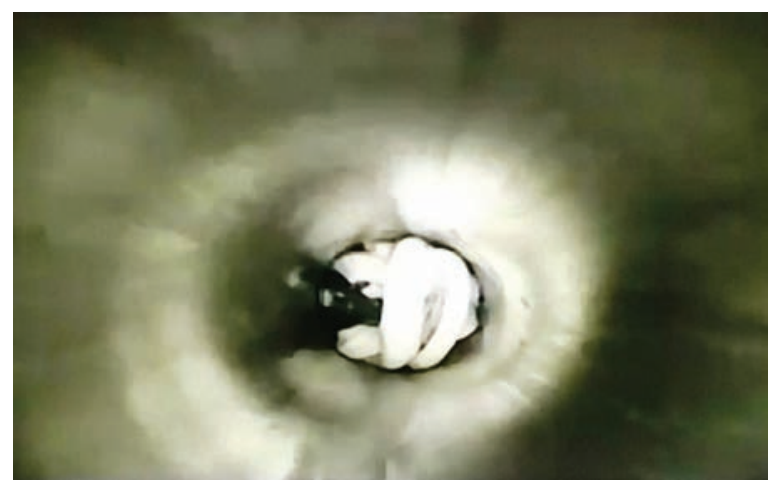

Figure (7): Extraction of specimen inside glove through umbilical port with synchronous withdrawn of laparoscope.

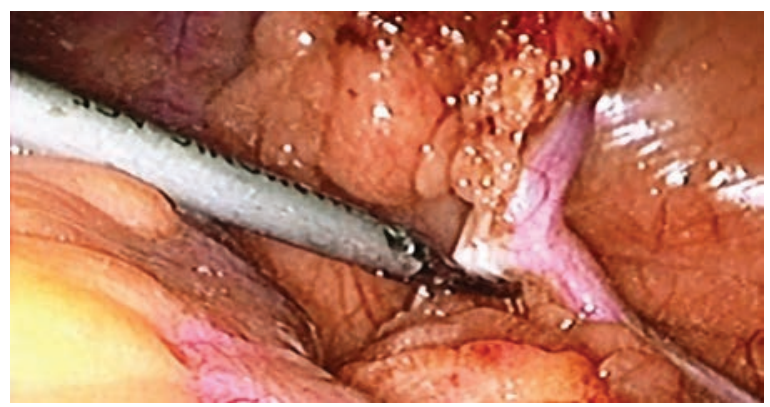

Figure (2): The Harmonic scalpel was used to control mesoappendix.

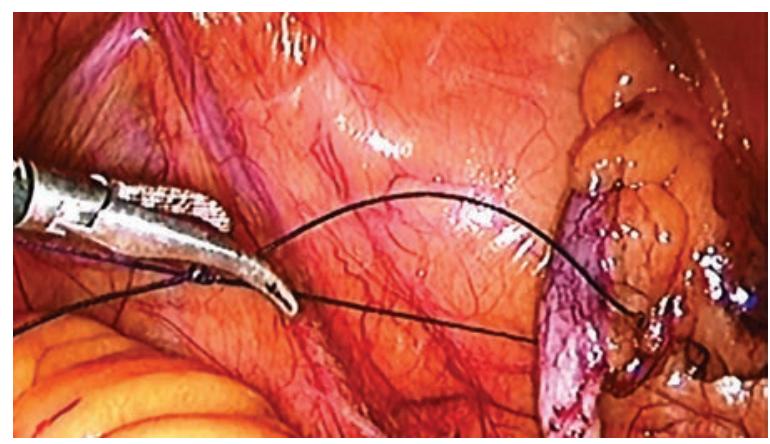

Figure (4): The base of the appendix was ligated using extracorporeal knot.

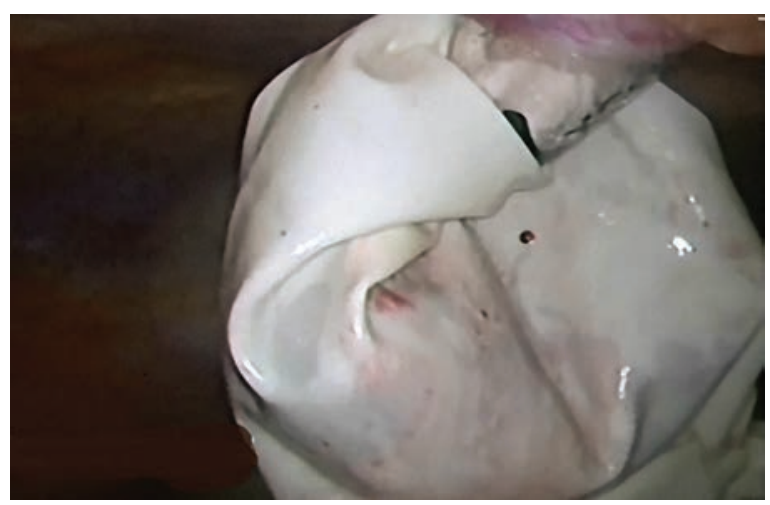

Figure (6): Extraction of specimen inside glove through umbilical port with using of 5 $\mathrm{mm}$ lens in Lt iliac fossa trocar.

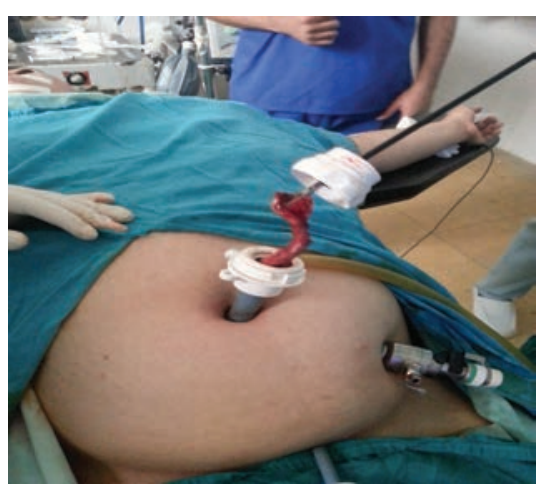

Figure (8): Extraction of specimen through umbilical trocar after using $5 \mathrm{ml}$ camera in LT iliac fossa port. 
Table (1): Comparison between the studied groups according to pre-operative variables.

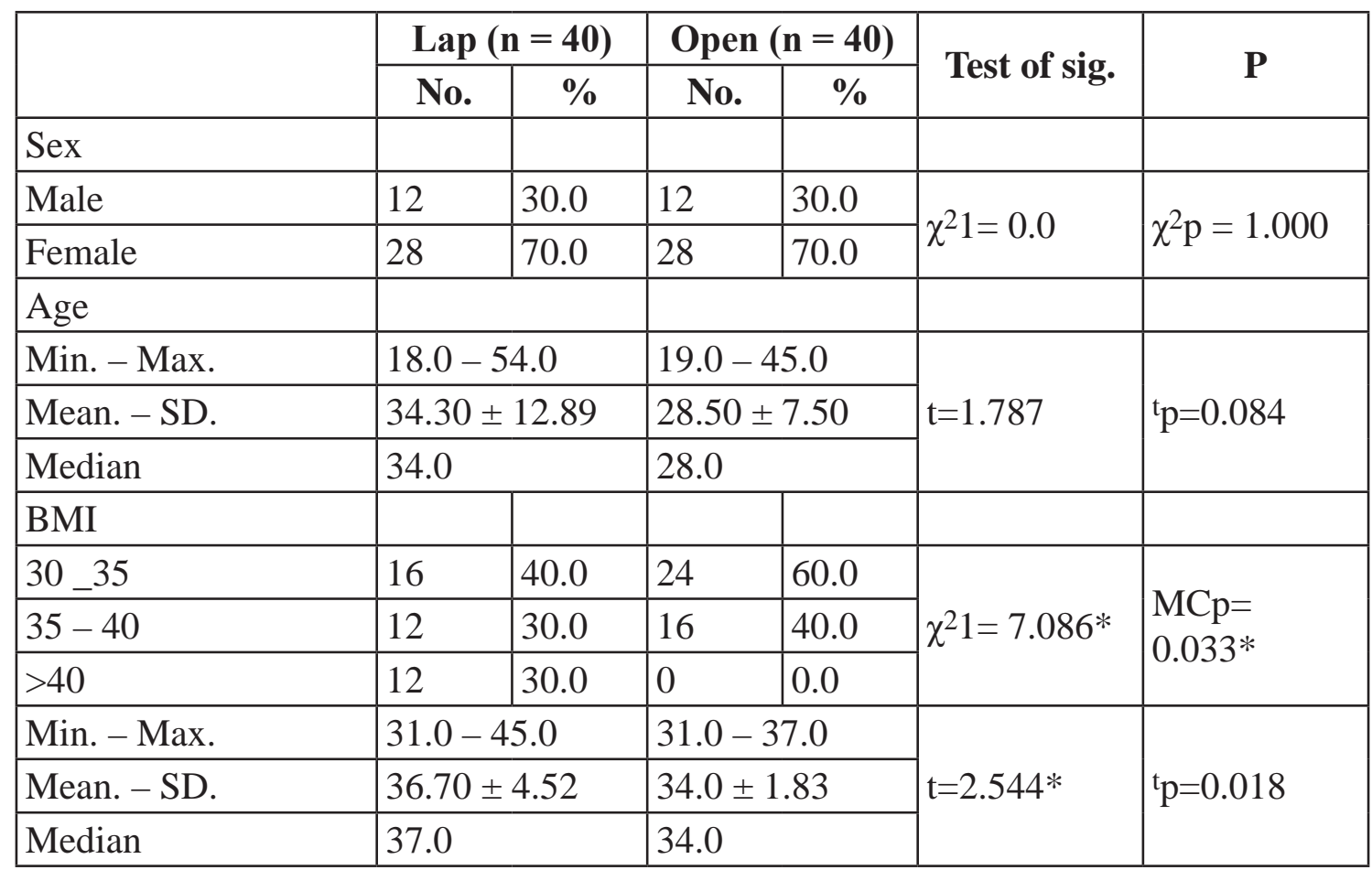

$\chi^{2} 1$ : value of Chi square

MC: Monte Carlo test.

Table (2): Comparison between the studied groups according to operative time.

\begin{tabular}{|c|c|c|c|c|}
\hline & Lap $(n=40)$ & Open $(n=40)$ & $\mathbf{T}$ & $\mathbf{P}$ \\
\hline $\begin{array}{l}\text { Operative tim } \\
\text { minutes) }\end{array}$ & & & & \\
\hline Min. - Max. & $55.0-120.0 \mathrm{~min}$ & $60.0-80.0 \mathrm{~min}$ & \multirow{3}{*}{1.686} & \multirow{3}{*}{0.106} \\
\hline Mean. - SD. & $77.20 \pm 23.04 \mathrm{~min}$ & $68.40 \pm 6.67 \mathrm{~min}$ & & \\
\hline Median & 70.0 & 66.0 & & \\
\hline
\end{tabular}

Table (3) : Comparison between the two studied groups according to operative difficulties.

\begin{tabular}{|l|l|l|l|l|l|l|}
\hline \multirow{2}{*}{} & \multicolumn{2}{|c|}{ Lap $(\mathbf{n}=\mathbf{4 0})$} & \multicolumn{2}{c|}{ Open $(\mathbf{n}=\mathbf{4 0})$} & \multirow{2}{*}{$\boldsymbol{\chi}^{\mathbf{2}}$} & \multirow{2}{*}{ P } \\
\cline { 2 - 5 } & No. & $\mathbf{9}$ & No. & $\mathbf{\%}$ & & \\
\hline Operative Difficult & & & & & & \\
\hline No & 34 & 85.0 & 32 & 80.0 & \multirow{2}{*}{0.173} & \multirow{2}{*}{$\mathrm{FE}_{\mathrm{p}}=1.000$} \\
\hline Yes & 6 & 15.0 & 8 & 20.0 & & \\
\hline
\end{tabular}

Table (4): Comparison between the two studied groups according to post-operative pain score.

\begin{tabular}{|l|l|l|c|}
\hline & Laparoscopic & \multicolumn{1}{c|}{ Open } & \multicolumn{1}{c|}{ P } \\
\hline Postoperative pain score & & & \\
\cline { 1 - 3 } Min. - Max. & $2.0-7.0$ & $4.0-9.0$ & \\
\cline { 1 - 2 } Mean \pm SD & $4.0 \pm 1.89$ & $6.40 \pm 1.71$ & $\operatorname{tp}<001$ \\
\cline { 1 - 3 } Median & 4.0 & 6.50 & \\
\hline
\end{tabular}


Table (5): Comparison between the two studied groups according to time to start oral feeding.

\begin{tabular}{|l|l|l|l|}
\hline & \multicolumn{1}{|c|}{ Laparoscopic } & \multicolumn{1}{c|}{ Open } & P \\
\hline Time to start oral feeding & & & \\
\cline { 1 - 3 } Min. - Max. & $4.0-12.0$ hours & $8.0-48.0$ & \multirow{2}{*}{ tp $=0.002$} \\
\cline { 1 - 3 } \pm Mean SD & $7.30 \pm 2.45$ & $18.10 \pm 13.25$ & \\
\cline { 1 - 3 } Median & 7 hours & 18.0 hours & \\
\hline
\end{tabular}

Table (6): Comparison between the two studied groups according to hospital stay.

\begin{tabular}{|c|c|c|c|}
\hline & Lap & Open & $\mathbf{P}$ \\
\hline \multicolumn{4}{|l|}{ Hospital stay } \\
\hline Min. - Max. & $0.50-2.0$ days & $1.50-3.50$ days & \multirow[t]{3}{*}{${ }^{\mathrm{MW}} \mathrm{p}<0.001$} \\
\hline Mean \pm SD & $1.35 \pm 0.58$ & $2.40 \pm 0.57$ & \\
\hline Median & 1.0 days & 2.50 days & \\
\hline
\end{tabular}

MW: Mann Whitney test.

Table (7): Comparison between the two studied groups according to postoperative complications.

\begin{tabular}{|l|l|l|l|l|l|}
\hline \multirow{2}{*}{} & \multicolumn{2}{|c|}{ Lap } & \multicolumn{2}{c|}{ Open } & \multirow{2}{*}{ P } \\
\cline { 2 - 6 } & No. & \multicolumn{1}{c}{$\%$} & No. & \% & \\
\hline Postoperative chest infection. & 6 & 15 & 8 & 20 & \multirow{2}{*}{${ }_{\mathrm{F}} \mathrm{p}=1.000$} \\
\hline Postoperative wound infection. & 4 & 15.0 & 16 & 40.0 & $\mathrm{c} 2=0.028$ \\
\hline Postoperative hernia. & 0 & 0.0 & 0 & 0.0 & - \\
\hline Postoperative fecal fistula. & 0 & 0.0 & 0 & 0.0 & - \\
\hline Postoperative intra-abdominal abscess. & 0 & 0.0 & 0 & 0.0 & - \\
\hline
\end{tabular}

$\chi^{2} \mathrm{p}$ : $\mathrm{p}$ value for Chi square test for comparing between the two studied groups.

at McBurney point. The appendix was sent postoperatively for histopathological examination. All the operative details including operative time were recorded. The patients were kept nil by mouth till the return of the bowel sounds. A soft diet, followed by regular diet, was introduced when the patients tolerated the liquid diet. The pain was measured qualitatively by using a visual analog scale. The length of the hospital stay was determined as the number of nights which were spent in the hospital. The patients were discharged after they resumed a regular diet, were afebrile and had good pain relief and after removal of drain if present. Patients were followed for post-operative complications were followed during the hospital stay and then every 2 weeks, then monthly. The patients were asked about their satisfaction regarding the cosmesis and gave a score out of 10 where zero was the least satisfaction and 10 was complete satisfaction.

Complicated perforated appendicitis was encountered in 5 patients (12.5\%) whom LA was attempted; while perforated appendicitis was found in 6 patients (15\%) managed with OA. Use of irrigation fluids to decrease contamination of peritoneal cavity and decrease manipulation of inflamed perforated appendix after both LA or OA followed by drain.

Statistical analysis: the data were analyzed by using the Statistical Package for Social Sciences. Continuous variables such as age, hospital stay, and operative time were presented as mean $\pm \mathrm{SD}$, while the categorical variables such as gender and post-operative complication were expressed as frequency 
and percentages by using a $90 \%$ confidence interval. The Student's t-test was used to compare the means of the continuous variables, while the categorical variables were compared by using the Chi-square $\chi^{2}$ and value of Chi-square $\chi^{2}$ or the Fisher's exact test FE as appropriate. A probability which was equal to or less than $0.05(\mathrm{P}<0.05)$ was considered as significant.

\section{Results:}

The comparisons of the patient's demographics and BMI are summarized in Table (1). No significant statistical differences were noted in both groups with respect to age, sex and BMI. The operative details and the postoperative characteristics are noted in Tables (2-6). The median operative time in the OA [66 min] group was slightly shorter than that in the LA [70 min] group Table (2).

The operative difficulties were encountered in 6 patients (15\%) and 8 patients (20\%) in LA and OA respectively Table (3). In group A (LA), another trocar was added in only 1 patient of the laparoscopic group which helped in traction of caecum in long subhepatic retrocecal appendix. In another patient, adherent omentum to previous paraumbilical hernioplasty incision was found which obscured and narrowed the field of laparoscope and led to difficulty in the retrieval of the appendix. Four cases of the five perforated appendicitis were difficult in manipulations and resection of appendix and abdominal lavage. The operations of LA (perforated and nonperforated appendicitis) were completed in all cases without converting any to open surgery. In group B (OA), two patients had long, retrocecal and subhepatic appendicitis; the caecum was fixed with deeply seated gangrene of the appendix was extending to the base in one patient; and the ligature of the appendicular artery was slipped and control of bleeding was done in another one patient. The remaining four cases from the six patients who presented with perforated appendicitis were difficult in manipulation of the appendix and abdominal lavage; ( all required extension of wound by muscle cutting and needed longer operative time to complete the procedure safely).

Post-operative pain was qualitatively noted according to the visual analog scale (VAS), it was significantly less in LA than in $\mathrm{OA}[\mathrm{P}<0.001]$, Table IV. Patients in LA started feeding earlier (7.30 \pm 2.45 hours) than OA (18.10 \pm 13.2 hours) and this was statistically significant $(\mathrm{P}<0.001)$, Table V. Two patients in OA got post-operative ileus for 48 hours and were managed conservatively. The postoperative hospital stay was (1.35 \pm 0.58 days) in the LA group as compared to $(2.40 \pm 0.57$ days) in the OA group, which was statistically significant $(p<0.0010)$, Table VI.

There was no statistically significant difference in chest infection rate between LA and OA. The difference between the wound infection rates was significantly higher in OA (20\%) in comparison to LA (5\%). Six patients in the OA group had abdominal wall abscess which required drainage and frequent dressing. Table VII, all cases of perforated appendicitis in OA group complicated by wound infection and abscess.

Patient's satisfaction to final cosmetic result was highly significant LA 9 in comparison to OA 4.5 according to the visual analog scale (VAS). Five cases had gall bladder disease and 4 cases ovarian cysts which were managed at the same procedure.

Postoperative follow up: All patients were subjected to postoperative follow up regularly to detect postoperative complications and access their satisfaction according to cosmesis. The follow up time ranged monthly for 12 months. In the laparoscopic group, 4 patients got wound infection immediate postoperatively (all presented with complicated perforated appendicitis) and were managed conservatively. In the open group, 16 cases got wound infection and 3 of them developed subcutaneous abscess which required drainage, packing and dressing twice daily with finally healing (the 6 patients with acute perforated appendicitis, 3 complicated by wound abscess and 3 complicated by wound infection).

\section{Discussion:}

In the last two decades, Laparoscopy has 
gained a lot of popularity around the world and became the most preferred surgical procedure for many abdominal surgeries like (gastrooesophageal reflux disease and gall bladder disease). Similarly, the same procedure is widely applied for appendectomy. In spite of a lot of case series and a large number of randomized clinical trials over more than two decades, the benefits of LA over OA are still controversial. ${ }^{24-26}$ With increasing prevalence of obesity all over the world, reaching a level of one third of populations, thus resulting in increasing numbers of obese patients will present for laparoscopic surgery. The open surgery usually result in high morbidity in obese patients like chest complications, deep vein thrombosis (DVT) and wound complications, beside technical difficulties to access through adipose tissue which result in inadequate visualization. ${ }^{27-29}$ In the early ages of laparoscopy, obesity was actually considered a contraindication for many operations including cholecystectomy. Despite these early concerns, with the laparoscopic approach has since become the gold standard approach for abdominal surgery in patients with increased body mass index. ${ }^{30-37}$

The results of the present study clearly demonstrated the superiority of laparoscopic appendectomy over open appendectomy in obese patients regarding the postoperative pain, hospital stay, cosmetic results, the functional status and the complication rates.

In the present study, LA could be safely performed in all cases, despite some operative difficulties is noted in 3 cases (the operations were complete in all cases without conversion to $\mathrm{OA}$ ). The results were comparable to and were less than other series. ${ }^{25,26}$ In five cases of LA, gall bladder disease was managed at the same session with laparoscopic cholecystectomy and the two procedures were done safely. In other 4 cases we found ovarian cyst and fenestration was done at same procedure. The peritoneal cavity can be completely visualized, examined, thus avoiding missing other pathology for abdominal pain.38 The high rate of misdiagnosis in females may be due to gynaecological problems and the female functional abnormalities. So, in a patient with suspected appendicitis, LA improves the diagnostic accuracy and also avoids unnecessary appendectomy. ${ }^{31}$

The operative duration in the present study was longer in the LA group as compared to that in the OA group. In most of the literature, the operating time in laparoscopic appendectomy was found to be more than that in open appendectomy; the difference of the mean time ultimately depends upon the experience of the surgeon and the competence of the team. The reasons for the prolongation include the extra steps for the setup (insufflations, trocar insertion and position modification), diagnostic laparoscopy and dealing with other pathologies. Our study was comparable with the following series of articles with respect to the operative duration. ${ }^{27,28,31}$ In Corneille et al study, 25 operative time in OA was longer than LA which explained by increase experience of surgeons in laparoscopy and adding converted cases to open group

The hospital stay in the present study was significantly less in LA than in OA [ $>24$ hours] and this was similar to the findings of other reported series. ${ }^{24-28,31} \mathrm{Li}$ et $\mathrm{al}^{27}$ metaanalyses study showed the laparoscopic approach led to a reduction in postoperative stay of 0.6 days. This may be explained by patients in LA started feeding early ,less tissue manipulation, less pain perception and avoiding large incisions in OA.

In the present study the post-operative pain is assessed by means of a VAS on the first day and this was quantitatively assessed by the daily requirements of analgesics. The pain was significantly less in the LA group. Meta analyses by Li et al 27 in 2010 supported the present study, mainly due to the less invasive nature of the procedure. Minimal trauma and less pain following LA allowed an early recovery. Fast resumption of a normal diet in LA was another added advantage due to the minimal handling of the bowel. This was similar to the findings of other reported 27 series but in Clarke et al study 35 it showed no difference.

In the present study chest infection was 
slightly higher in OA than LA and this was similar to series. ${ }^{33,34}$ This is due to early ambulation, less pain, less cutting and trauma to abdominal muscles in LA. Wound infection was high in OA than LA due to bigger incision in poorly vascularized adipose tissue, direct contamination to wound edges by inflamed appendix and infected fluid, muscle cutting in some cases and increase rate of DM in obese patients in comparison to minimal incisions and tissue trauma in LA. This was similar to studies comparing the two approaches. ${ }^{24-28,31,34}$

Many literature searches and meta analyses showed that there was high risk of intra-abdominal abscess in LA than $\mathrm{OA}^{26,32}$ studies, but we did not have any intraabdominal abscesses in the present study. Clarke et al study, ${ }^{35}$ believed that mastery of the learning curve and the use of the standard guide lines definitely reduced the incidence of the intra-abdominal abscesses.

As regard patient satisfaction about final cosmetic result, it was higher in LA in comparison to OA when assessed by VAS .This may be explained by small incisions in LA two of them are hidden in natural camouflages (umbilicus and suprapubic hair) and less wound complications in comparison to OA with large incision. This is similar to series. ${ }^{27,32,39}$

\section{Conclusion:}

The present study concluded that: the change in surgical approach in managing acute perforated and nonperforated appendicitis is safe and effective. The present study shows that LA provides considerable benefits over OA and was found to be superior to OA in obese patients with respect to the postoperative pain, hospital stay, early recovery, cosmesis and lower complication rate. Laparoscopic appendectomy also improves diagnostic ability and excludes other causes of abdominal pain and gives the ability to manage other pathology at the same session. The widespread use of LA is recommended in hospitals where laparoscopic expertise and equipments are available.

\section{Reference:}

1- Ohmann C, Franke C, Kraemer M, Yang Q: Status report on epidemiology of acute appendicitis. Der Chirurg 2002; 73: 769-776.

2- McBurney C IV: The incision made in the abdominal wall in cases of appendicitis, with a description of a new method of operating. Ann Surg 1894; 20: 38-43.

3- Semm K: Endoscopic appendectomy. Endoscopy 1983; 15: 59-64.

4- Cox MR, McCall JL, Toouli J, et al: Prospective randomized comparison of open versus laparoscopic appendectomy in men. World J Surg 1996; 20: 263-266.

5- Scott R, Brent W, Klaus T: Single-incision laparoscopic cholecystectomy using conventional instruments: Early experience in comparison with the gold standard. $J \mathrm{Am}$ Coll Surg 2009; 209: 632-637.

6- Tacchino R, Greco F, Matera D: Single incision laparoscopic cholecystectomy: Surgery without a visible scar. Surg Endosc 2009; 59: 254-255

7- Shaikh AR, Sangrasi AK, Shaikh GA: Clinical outcomes of laparoscopic versus open appendectomy. JSLS 2009; 13: 574-580.

8- Sauerland S, Lefering R, Neugebauer EA: Laparoscopic versus open in suspected appendicitis. Cochrane Database Syst Rev 2002: CD001546.

9- Guller U, Hervey S, Purves H: Laparoscopic versus open appendectomy; comparison based on a large administrative database. Ann Surg 2004; 239: 43-52.

10- Olmi S, Magnone S, Bertolini A, Croce E: Laparoscopic versus open appendectomy in acute appendicitis: A randomized study. Surg Endosc 2005; 19: 1193-1195.

11- Kaplan M, Salman B, Yilmaz TU, Oguz M: A quality of life laparoscopic and open approaches in acute appendicitis: A randomized prospective study. Acta Chir Belg. 2009; 109: 356-363.

12- Hussain A, Mahmood H, Singhal T, Balakrishnan S, El-Hasani S: Appendectomy in a district hospital: Does the technique influence the outcome? J Laparoendosc Adv Surg Tech A 2008; 18: 204-208.

13- Konstantinidis KM, Anastasakou KA, Vorias MN, Sambalis GH, Georgiou MK, Xiarchos AG: A decade of laparoscopic appendectomy: presentation of 1,026 patients with suspected appendicitis treated in a single surgical department. J Laparoendosc Adv Surg Tech A 2008; 18: 248-258. 
14- Varela JE, Hinojosa MW, Nguyen NT: Laparoscopy should be the approach of choice for acute appendicitis in the morbidly obese. Am J Surg 2008; 196: 218-222.

15- Harrell AG, Lincourt AE, Novitsky YW, et al: Advantages of laparoscopic appendectomy in the elderly. Am Surg 2006; 72:474-480.

16- Pokala N, Sadhasivam S, Kiran RP, Parithivel $\mathrm{V}$ : Complicated appendicitis disease, the laparoscopic approach appropriate? A comparative study with the open approach: outcome in a community hospital setting. Am Surg 2007; 73: 737-742.

17- Katkhouda N, Friedlander MH, Grant SW, et al: Intra abdominal abscess rate after laparoscopic appendectomy. Am J Surg 2000; 180: 456-461.

18- Golub R, Siddiqui F, Pohl D: Laparoscopic versus open appendectomy: A meta analysis. J Am Coll Surg 1998; 186: 545-553.

19- Park HC, Yang DH, Lee BH: The laparoscopic approach for perforated appendicitis, including cases complicated by abscess formation. J Laparoendosc Adv Surg Tech A 2009; 19: 727-730.

20- Malagon AM, Arteaga-Gonzalez I, Rodriguez-Ballester L: Outcomes after laparoscopic treatment of complicated versus uncomplicated acute appendicitis: A prospective, comparative trial. $J$ Laparoendosc Adv Surg Tech A 2009; 19: 721-725.

21- Ball CG, Kortbeek JB, Kirkpatrick AW, Mitchell P: Laparoscopic appendectomy for complicated appendicitis: An evaluation of postoperative factors. Surg Endosc 2004; 18: 969-973.

22- So JB, Chiong EC, Chiong E: Laparoscopic appendectomy for perforated appendicitis. World J Surg 2002; 26: 1485-1488.

23- Vogt DM, Curet MJ, Pitcher DE, Martin DT, Zucker KA: Preliminary results of a prospective randomized trial of laparoscopic onlay versus conventional inguinal herniorrhaphy. Am J Surg 1995; 169(1): 849; discussion 89-90.

24- Kargar S, Mirshamsi MH, Zare M, Arefanian S, ShadmanYazdi E, Aref A: Laparoscopic versus open appendectomy; which method to choose? A prospective randomized comparison. Acta Med Iran 2011; 49(6): 352-356.

25- Corneille MG, Steigelman MB, Myers JG, Jundt J, Dent DL, Lopez PP et al: Laparoscopic appendectomy is superior to open appendectomy in obese patients. Am J Surg 2007; 194(6): 877-880; discussion 880-881.

26- Sauerland S, Jaschinski T, Am Neugebauer E: Laparoscopic versus open surgery for suspected appendicitis. Cochrane Database Syst Rev 2010; (10): CD001546.

27- Li X, Zhang J, Sang L, Zhang W, Chu $Z$, Li $X$ et al: Laparoscopic versus conventional appendectomy-a meta-analysis of randomized controlled trials. BMC Gastroenterol 2010; 10: 129.

28- Ali A, Chowdhury M, Rouf H, Yusuf OF, Islam S: Laparoscopic versus open appendicectomy: A randomized controlled trial. J Bangladesh Coll Phys Surg May 2009; 27(2): 82-90.

29- Mokdad AH, Ford ES, Bowman BA, Dietz WH, Vinicor F, Bales VS et al: Prevalence of obesity, diabetes, and obesity-related health risk factors, 2001. JAMA 2003; 289(1): 76-79.

30- Schauer PR, Ikramuddin S: Laparoscopic surgery for morbid obesity. Surg Clin North Am 2001; 81(5): 1145-1179.

31- Ortega AE, Hunter JG, Peters JH, Swanstrom LL, Schirmer B: A prospective, randomized comparison of laparoscopic appendectomy with open appendectomy. Laparoscopic Appendectomy Study Group. Am J Surg 1995; 169(2): 208-212; discussion 212-213.

32- Shah B, Vaidhya N, Anchalia MM: A comparative study between laparoscopic appendicectomy and small incision open (Minilap) appendicectomy in cases of acute appendicitis. International Journal of Science and Research (IJSR) 2013; 2(11): 144-150.

33- Nguyen NT, Zainabadi K, Mavandadi S, Paya M, Stevens CM, Root J et al: Trends in utilization and outcomes of laparoscopic versus open appendectomy. Am J Surg 2004; 188(6): 813-820.

34- Mason RJ, Moazzez A, Moroney JR, Katkhouda N: Laparoscopic vs Open Appendectomy in Obese Patients: Outcomes using the american college of surgeons national surgical quality improvement program database. J Am Coll Surg 2012; 215(1): 88-99.

35- Clarke T, Katkhouda N, Mason RJ, Cheng BC, Olasky J, Sohn HJ et al: Laparoscopic versus open appendectomy for the obese patient: A subset analysis from a prospective, randomized, double-blind study. Surg 
Endosc 2011; 25(4): 1276-1280.

36- Alis H, Gonenc M, Deniztas C, Kapan S, Turhan AN: Metal endoclips for the closure of the appendiceal stump in laparoscopic appendectomy. Tech Coloproctol 2012; 16(2): 139-141.

37- Kurtz RJ, Heimann TM: Comparison of open and laparoscopic treatment of acute appendicitis. Am J Surg 2001; 182(3): 211-214.
38- Moberg AC, Montgomery A: Introducing diagnostic laparoscopy for patients with suspected acute appendicitis: Surg Endosc 2000; 14(10): 942-947.

39- Goudar BV, Telkar S, Lamini YP, Shirbur SN, Shailesh ME: Laparoscopic versus open appendectomy: A comparison of primary outcome studies from southern India. Journal of Clinical and Diagnostic Research 2011; 5(8): 1606-1609. 